\title{
A Density Functional Theory Investigation of the Reaction of Water with $\mathrm{Ce}_{2} \mathrm{O}^{-}$
}

\author{
Hassan Harb and Hrant P. Hratchian* \\ Department of Chemistry and Chemical Biology $\&$ Center for Chemical Computation and \\ Theory, University of California, Merced \\ E-mail: hhratchian@ucmerced.edu
}




\begin{abstract}
Cerium suboxide clusters have been shown to react with water to yield $\mathrm{H}_{2}$. Since reactions of metal oxides with water are of great fundamental and practical importance in energy science, detailed study of this reaction can provide new key knowledge for future catalyst design. Using density function theory calculations, we identified and report complete reaction pathways for two spin-states of $\mathrm{Ce}_{2} \mathrm{O}^{-}$reacting with $\mathrm{H}_{2} \mathrm{O}$. Additionally, examining the molecular orbitals of initial and final cerium oxide clusters, we found that metal d electrons facilitate the reduction of water. This work provides new understanding of this reaction and insights to the reactivity enhancements for cerium-doped surfaces.
\end{abstract}

\title{
Introduction
}

Water, being one of the most abundant substances in nature, has been the subject of intense interest for scientists to study its physical and chemical properties. ${ }^{1-11}$ In addition to the various roles water plays in different families of chemical reactions and biological systems, $\mathrm{H}_{2} \mathrm{O}$ has been a key focus in energy related research. Of particular interest are catalysts facilitating the four-electron $2 \mathrm{H}_{2} \mathrm{O} \longrightarrow 2 \mathrm{H}_{2}+\mathrm{O}_{2}$ reaction. ${ }^{12-17}$ Cerium oxides attracted special interest recently due to their ability to efficiently catalyze a wide range of oxidation and reduction reactions, including water-gas shifting reactions. ${ }^{18-22}$ Several studies have also shown that cerium oxide-supported metal surfaces exhibit increased catalytic activity relative to their non-cerium oxide supported analogues. ${ }^{23-35}$

Surface defects due to metal or oxide deficiencies possess unique electronic properties and facilitate increased reactivity. As with other metal oxides, the catalytic activity of lanthanide oxide surfaces is most active at surface defect sites. However, studying extended surfaces is complicated by the low concentration of surface defects and the continuous structural changes along the surfaces. Defect sites exhibit incomplete valencies and localized electronic structures, ${ }^{36}$ thus they pose as model systems to study reactivity on surface defects on 
catalytic surfaces.

While the partially filled f-manifold in most lanthanide complexes lies close to the $5 \mathrm{~d}$ and 6s orbitals of the lanthanide centers, it is non-bonding in nature and exhibits core-like behavior. Several studies have shown that the orbitals involved in chemical processes on lanthanides and lanthanide-based clusters involve $6 \mathrm{~s}$ and $5 \mathrm{p}$ orbitals, while the occupation number of $4 \mathrm{f}$ orbitals remains intact. ${ }^{37-43}$

Several experimental and computational studies have been performed on cerium oxide clusters in order to better understand the electronic structure features that pave the way to a thorough understanding of their reactivity and catalytic activity. In addition, various experimental and theoretical studies have explored the reactivity of classes of cerium-based clusters with various gas-phase small molecules. ${ }^{17,19,39,42,44-56}$ Of particular interest here are computational studies conducted by Zhou and co-workers on the reactivity of $\mathrm{Ce}_{\mathrm{n}}(\mathrm{n}=1-3)$ with up to six water molecules. ${ }^{44,45}$ Their results indicate high reactivity of these cerium clusters and their efficiency in decomposing multiple water molecules. Recently, Jarrold and co-workers reported mass spectra of $\mathrm{Ce}_{\mathrm{x}} \mathrm{O}_{\mathrm{y}}{ }^{-}$systems $(\mathrm{x}=2,3, \mathrm{y}=1-4)$ and their respective products of the clusters and water. ${ }^{17}$ Their results indicate that cerium oxide clusters undergo three types of reactions: hydrogen gas production, water abstraction, and hydroxide abstraction. The relative selectivity of one reaction type over the others is highly dependent on the stoichiometry of the cluster. For example, $\mathrm{Ce}_{2} \mathrm{O}^{-}, \mathrm{Ce}_{3}{ }^{-}, \mathrm{Ce}_{3} \mathrm{O}_{2}{ }^{-}$, and $\mathrm{Ce}_{3} \mathrm{O}_{2}{ }^{-}$ preferentially produce $\mathrm{H}_{2}$ gas, while clusters with equal stoichiometric ratios of $\mathrm{Ce}$ and $\mathrm{O}$ undergo $-\mathrm{OH}$ abstraction, and clusters bearing more oxygens than ceriums undergo water abstraction.

In order to investigate the mechanism of water reactivity with cerium oxide clusters, we consider the simplest stoichiometric cluster that is capable of efficiently producing $\mathrm{H}_{2}$ gas, namely $\mathrm{Ce}_{2} \mathrm{O}^{-}$. We first examine the geometric and electronic structure of different gasphase clusters potentially involved in the reaction. Obtained experimental results include data from mass-spectrometry and photoelectron spectroscopy which supply us with valuable 
information on the geometric and electronic structures of the studied molecules. To this extent, we map the potential energy surface of the studied reaction by altering the relative positions of cerium, oxygen, and, when necessary, hydrogen atoms as well. In addition, for each conformation, we optimize the geometry under several spin-states and investigate the relative stabilities of these states. In this paper we present an exploration of the reaction of $\mathrm{Ce}_{2} \mathrm{O}^{-}$with water to provide a clear mechanistic explanation of the overall chemical process.

\section{Computational Methods}

Calculations were performed using a development version of the GAUSSIAN suite of electronic structure programs. ${ }^{57}$ The B3PW91 density functional was employed. ${ }^{58-62}$ The unrestricted formalism was used for all calculations. ${ }^{63}$ The Stuttgart relativistic small core atomic natural orbital basis set and corresponding effective core potential (ANO/ECP) basis set with 28 core electrons and a contracted valence basis set (14s13p10d8f6g) [6s6p5d4f3g] for cerium center. ${ }^{64}$ The Dunning style correlation-consistent basis set aug-cc-pVTZ was used for oxygen and hydrogen centers. ${ }^{65,66}$ Geometry optimizations were carried out using standard methods and the nature of all located potential energy surface stationary points were confirmed by vibrational frequency analysis. ${ }^{67}$ Intrinsic reaction coordinate (IRC) calculations were performed to ensure that optimized transition structures connect appropriate potential energy surface minima. ${ }^{68,69}$ For all stationary points along the reaction pathways, all reasonable spin-states were calculated. The stability of all calculated Kohn-Sham determinants was

verified. ${ }^{70-72}$ Reported enthalpies of reactions were calculated at $298 \mathrm{~K}$. Relative energies including zero-point corrections at $0 \mathrm{~K}$ are reported in the supporting information.

\section{Results and Discussion}

In what follows, structures are labeled as $X$-n, where $X=A, B, C \ldots$ represents a particular molecular structure, and the value of $\mathrm{n}$ indicates the multiplicity of the cluster. Transition 
structures are labeled as TS1- $n$ and TS2-n, where $n$ also represents the spin multiplicity of the transition structure. As shown in Scheme 1, the reaction proceeds via the addition of water to a cerium center $(\mathbf{A} \longrightarrow \mathbf{G})$, followed by formation of a hydride bridge between cerium atoms $(\mathbf{G} \longrightarrow \mathbf{H})$. This is followed by formation of complex $\mathbf{I}$, which features a bridging hydroxide ligand. The last step yields evolution of $\mathrm{H}_{2}$ and formation of $\mathrm{Ce}_{2} \mathrm{O}_{2}{ }^{-}$.

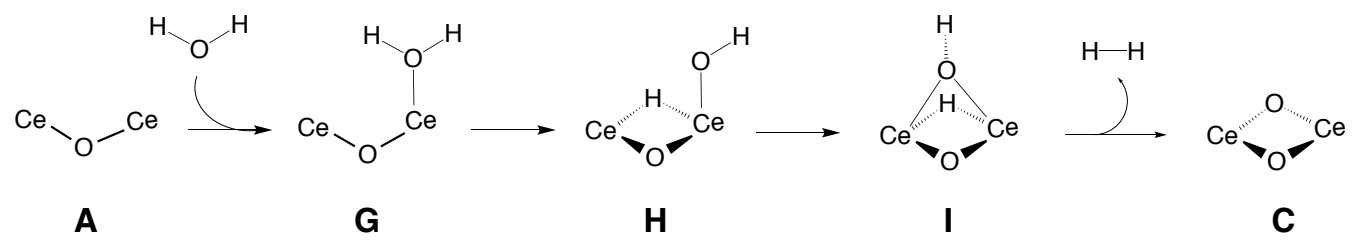

Scheme 1: Overview of the proposed mechanism

\section{Reactant and Product Cerium Oxide Clusters}

The first step of exploring the mechanism of $\mathrm{Ce}_{2} \mathrm{O}^{-}+\mathrm{H}_{2} \mathrm{O} \longrightarrow \mathrm{Ce}_{2} \mathrm{O}_{2}{ }^{-}+\mathrm{H}_{2}$ is to determine the initial structure of $\mathrm{Ce}_{2} \mathrm{O}^{-}$. In order to do so, various molecular structures and electronic configurations were studied. For a $\mathrm{Ce}_{2} \mathrm{O}^{-}$molecule, two general structures can be considered: (1) the oxygen atom can bridge the two cerium atoms; or (2) the oxygen can be a terminal and bound to one cerium only. In addition to the molecular structure, we accounted for the possible existence of several spin-states. We performed our calculations on the ground-state quartet in addition to doublet and the sextet multiplicities.

Our calculations showed that several different structures of $\mathrm{Ce}_{2} \mathrm{O}^{-}$species exist. Figure 1 shows all competitive $\mathrm{Ce}_{2} \mathrm{O}^{-}$species. The ground state of $\mathrm{Ce}_{2} \mathrm{O}^{-}$, shown in Fig. 1 as $\mathbf{A}-4$, is a quartet state featuring a bridging oxide. In this structure, the two $\mathrm{Ce}-\mathrm{O}$ bonds are equivalent with a bond length of 2.06 Aand a Ce-O-Ce angle of $120.8^{\circ}$. Two other closely lying states, both having bridging oxides were located. The first is the sextet (A-4), lying $3.92 \mathrm{kcal} / \mathrm{mol}$ higher than $\mathbf{A}-4$ and the doublet state $(\mathbf{A}-\mathbf{2})$ which is $9.88 \mathrm{kcal} / \mathrm{mol}$ higher in energy than the ground state. These results are in agreement with the anion photoelectron spectroscopy results published by Kafader et $a l .{ }^{39}$ Another located structure, B-6, features 
a terminal oxide rather than bridging and has a sextet spin ground state. This structure is much higher in energy than the others; it is $48.40 \mathrm{kcal} / \mathrm{mol}$ higher than A-4. Quartet and doublet states were not found for this structure. Despite the fact that B-6 is much higher in energy than the other three structures, we still considered the possibility of its role in the reaction with water and consequent $\mathrm{H}_{2}$ production. Yet, calculations that considered B-6 to be the structure for the initial $\mathrm{Ce}_{2} \mathrm{O}^{-}$reactant did not yield any conclusive results.

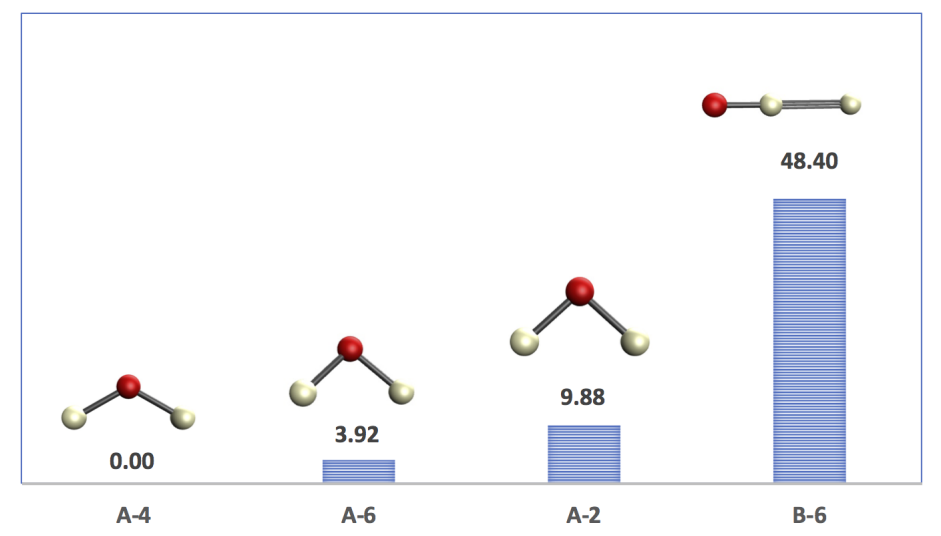

Figure 1: Optimized structures of $\mathrm{Ce}_{2} \mathrm{O}^{-}$and their relative energies given in $\mathrm{kcal} / \mathrm{mol}$.

In order to determine the various geometric structures of the product cluster species $\mathbf{C}$, $\mathrm{Ce}_{2} \mathrm{O}_{2}{ }^{-}$, we consider different variations in the positions of oxygens relative to the cerium centers. As for $\mathbf{A}$ and $\mathbf{B}$ above, each oxide can either be at terminal positions relative to a cerium atom or bridging the two cerium centers. We have calculated various combinations of terminal and bridging geometric configurations.

Figure 2 shows the various identified $\mathrm{Ce}_{2} \mathrm{O}_{2}{ }^{-}$structures and their relative energies. The ground-state structure, $\mathbf{C - 4}$, is a quartet planar structure where both oxygens are bridging the two cerium atoms. Another closely lying state is doublet C-2, which has a geometry similar to the ground-state. C-2 lies only $0.63 \mathrm{kcal} / \mathrm{mol}$ higher than $\mathbf{C - 4}$, and the geometries of the two structures are quite similar.

Compounds C-6 and F-2 lie approximately $25 \mathrm{kcal} / \mathrm{mol}$ higher in energy than C-2 and C-4. C-6 is a sextet and is $24.94 \mathrm{kcal} / \mathrm{mol}$ higher in energy than C-4. Although the structure of C-6 is similar to $\mathbf{C - 4}$ and C-2, C-6 is not a planar structure. In fact, the $\mathrm{Ce}-\mathrm{O}-\mathrm{Ce}-\mathrm{O}$ 
torsion angle is $20.3^{\circ}$, unlike $\mathbf{C}-4$ and $\mathbf{C}-2$, which have $\mathrm{Ce}-\mathrm{O}-\mathrm{Ce}-\mathrm{O}$ torsion angles of $0^{\circ}$.

An additional set of higher energy $\mathrm{Ce}_{2} \mathrm{O}_{2}{ }^{-}$isomers have also been found and are labeled D- $n, \mathbf{E}-n$, and $\mathbf{F}-n$. The geometry of $\mathbf{F - 2}$, which is only $2.2 \mathrm{kcal} / \mathrm{mol}$ higher in energy than C-6, is quite different. Specifically. one oxide is terminal while the other one is bridging. Given that D-2, D-4, D-6, E-2, E-4, E-6, and F-6 are all much higher in energy (58.73 $162.47 \mathrm{kcal} / \mathrm{mol}$ ) we presume that they do not contribute to the mechanistic study presented in this paper and do not consider them further.

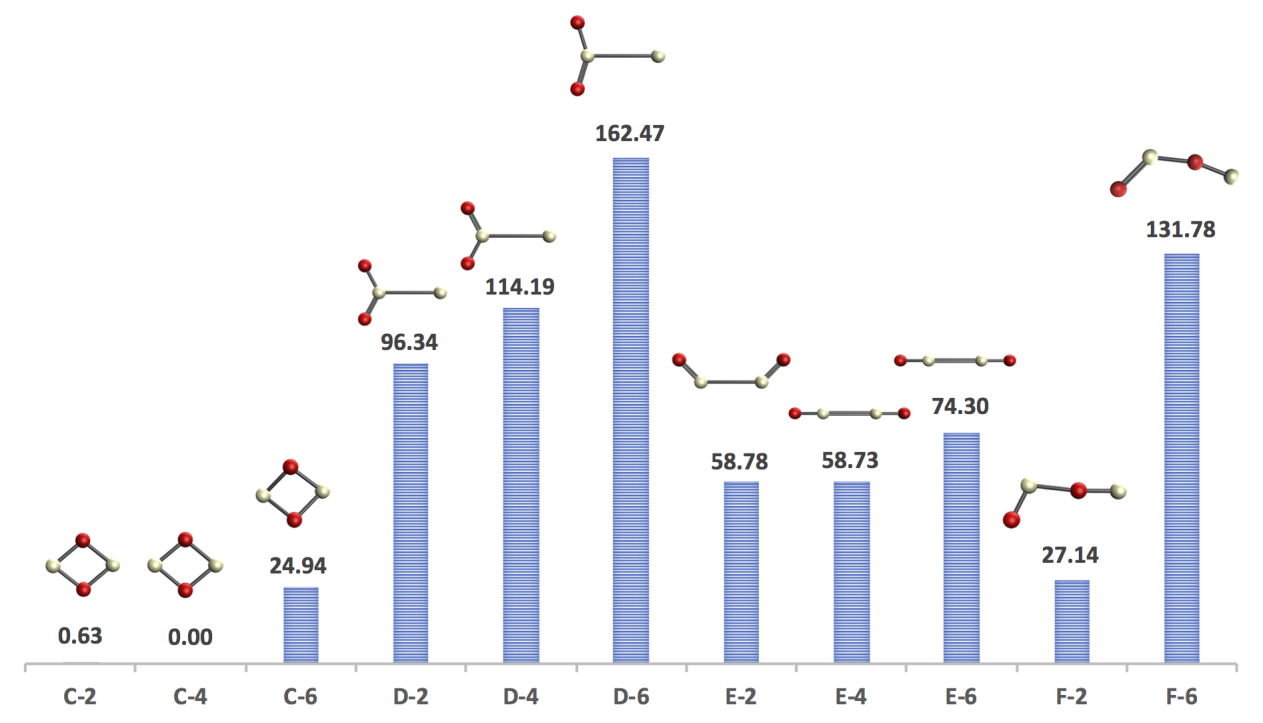

Figure 2: Optimized structures of $\mathrm{Ce}_{2} \mathrm{O}_{2}{ }^{-}$and their relative energies given in kcal $/ \mathrm{mol}$.

In their study, Kafader et al. reported the anion photoelectron spectra of $\mathrm{Ce}_{2} \mathrm{O}^{-}$and $\mathrm{Ce}_{2} \mathrm{O}_{2}{ }^{-}$is reported alongside a computational analysis to fully characterize the observed structures. ${ }^{39}$ DFT calculations and Franck-Condon simulations were used to determine that the ground-state configuration of $\mathrm{Ce}_{2} \mathrm{O}^{-}$is a ${ }^{4} \mathrm{~A}_{2}$ state with the $\mathrm{Ce}-\mathrm{O}-\mathrm{Ce}$ bridge bonding being the favored structural motif, resulting in $C_{2 v}$ symmetry. Another close-lying state was found, a ${ }^{2} \mathrm{~A}_{2}$ with a bonding motif resembling the ground-state quartet. These two structures correspond to A-2 and A-4 structures reported in Fig. 1. Using the same approach, Kafader et al. determined the ground-state configuration for $\mathrm{Ce}_{2} \mathrm{O}_{2}{ }^{-}$to be a ${ }^{4} \mathrm{~A}$ g state with the ${ }^{2} \mathrm{~A}_{\mathrm{g}}$ state being slightly higher in energy. Both structures exhibit $D_{2 h}$ symmetry and Franck- 
condon simulations confirmed their contributions to the photoelectron spectrum. These two structures resemble $\mathbf{C - 4}$ and $\mathbf{C - 2}$ shown in Fig. 2, respectively. As far as the starting materials and the final products are concerned, our computational results are in good agreement with the results reported by Kafader and coworkers. Thus, the two potential energy surfaces to be explored are the ${ }^{4} \mathrm{~A}_{2}$ and ${ }^{2} \mathrm{~A}_{2}$ routes leading to ${ }^{4} \mathrm{~A}_{\mathrm{g}}$ and ${ }^{2} \mathrm{~A}_{\mathrm{g}}$, respectively. Following up on this, we aim to explore the mechanistic studies of the reactions of $\mathbf{A}-\mathbf{2}$ and $\mathbf{A}-\mathbf{4}$ with water to produce $\mathbf{C - 2}$ and $\mathbf{C}-\mathbf{4}$ alongside $\mathrm{H}_{2}$.

\section{Water Addition}

We have identified one unique mode for eater addition to A-2 and A-4 clusters. This mode is best described as an interaction between the water oxygen and a terminal cerium atom, while the second cerium atom does not directly engage in this step. Water addition to the $\mathrm{Ce}_{2} \mathrm{O}^{-}$clusters forms structures G-2 and G-4. A distinctive feature about both adduct structures is that a water hydrogen is oriented towards the distant cerium, suggesting the feasibility of proton transfer to the remote cerium center.

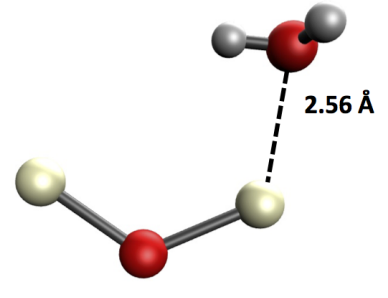

G-4 $\Delta H=-12.2$

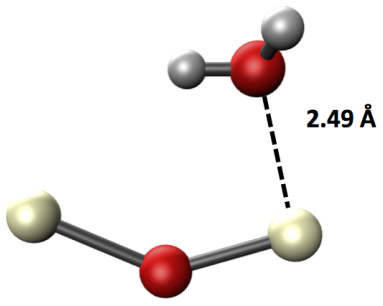

G-2 $\Delta H=-23.3$

Figure 3: Quartet G-4 (left) and doublet G-2 (right) with intermolecular distances given in Angstroms and relative energies given in $\mathrm{kcal} / \mathrm{mol}$.

The relative heats of reactions of the water adducts are also shown in Fig. 3. Formations of both adducts resulting from water addition to $\mathrm{Ce}_{2} \mathrm{O}^{-}$are exothermic, with $\Delta \mathrm{H}$ values of -23.3 and $-12.2 \mathrm{kcal} / \mathrm{mol}$ for the doublet and quartet states, respectively. For the two formed intermediates the distance between the water oxygen center and the cerium atom is $2.56 \AA$ 
(G-4) and $2.49 \AA$ (G-2). Moreover, as the oxygen approaches $\mathrm{Ce}_{2} \mathrm{O}^{-}$, one of the hydrogens from the water molecule orients towards the position of the cerium atoms, indicating the first step towards breaking the $\mathrm{O}-\mathrm{H}$ bond and consequent formation of a new $\mathrm{Ce}-\mathrm{H}$ bond. An interesting aspect of water addition to the cerium oxide cluster is the activation of the aquaoxygen by the $\mathrm{Ce}$ center, which precedes $\mathrm{O}-\mathrm{H}$ bond cleavage. Instead, the interaction of the lone pairs on the oxygen of the water with the electron-deficient cerium center provides an incentive to proceed with an energetically-favored water addition to $\mathrm{Ce}_{2} \mathrm{O}^{-}$through direct addition via the water oxygen onto the cluster. Unlike the behavior of transition metal oxides and their reactions with water, ${ }^{73}$ the mode of water addition in $\mathrm{Ce}_{2} \mathrm{O}^{-}$does not involve initial interaction between the water hydrogens and a cluster oxide site. Instead, the interaction of the water lone pairs with the electron deficient cerium center initiates an energetically favorable water addition to $\mathrm{Ce}_{2} \mathrm{O}^{-}$through direct addition via the water oxygen to the cluster.

\section{Hydride Bridge Formation}

Following water addition, the reaction undergoes $\mathrm{Ce}$ oxidation as a water $\mathrm{O}-\mathrm{H}$ bond is cleaved and leads to formation of a bridging hydride. Structures $\mathbf{H}-\mathbf{2}$ and $\mathbf{H}-\mathbf{4}$ correspond to these intermediates, $\mathrm{Ce}_{2} \mathrm{HO}(\mathrm{OH})^{-}$that form from $\mathrm{O}-\mathrm{H}$ bond cleavage in $\mathrm{G}-2$ and $\mathrm{G}$ 4, respectively. Figure 4 shows the structure and relative energies of two identified spin states that correspond structure H. Both doublet and quartet states of structure $\mathrm{H}$ bear the same geometry. The oxygen and hydrogen centers in the ring are both in bridging positions relative to the two cerium atoms. The bridging hydride binds to the Ce centers with bond lengths of $2.29 \AA$ and $2.30 \AA$ for both the doublet and quartet species. The structure of $\mathbf{H}-\mathbf{2}$ and $\mathbf{H}-\mathbf{4}$ is best described as a four-membered planar ring consisting of two cerium atoms, an oxygen, and a hydrogen, with a bound hydroxide ligand. The $\mathrm{O}-\mathrm{H}$ bond cleavage in both the quartet and doublet states is exothermic with heats of reaction of $-73.0 \mathrm{kcal} / \mathrm{mol}$ (quartet state) and $-81.6 \mathrm{kcal} / \mathrm{mol}$ (doublet) relative to their respective starting materials. 
Such exothermicity suggests the formation of each of $\mathbf{H - 2}$ and $\mathbf{H}-\mathbf{4}$ is highly favorable.

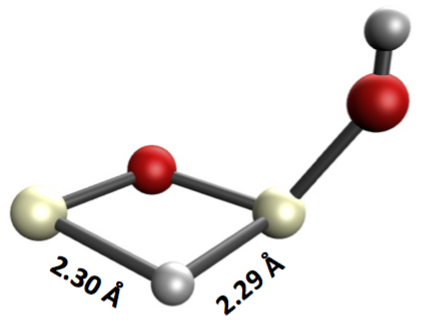

$\mathrm{H}-4$ $\Delta H=-73.0$

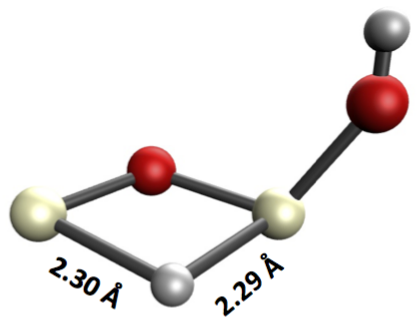

H-2

\section{$\Delta \mathrm{H}=\mathbf{- 8 1 . 6}$}

Figure 4: Structures of quartet $\mathrm{H}-4$ and doublet $\mathrm{H}-2, \mathrm{Ce}-\mathrm{O}$ distances are shown in units of Angstroms and relative energies are shown in $\mathrm{kcal} / \mathrm{mol}$.

Transition structures connecting G-2 to $\mathbf{H}-\mathbf{2}$ and $\mathbf{G}-\mathbf{4}$ to $\mathbf{H}-\mathbf{4}$ have been identified and verified by calculating analytic frequencies and intrinsic reaction coordinates. These transition structures are shown in Fig. 5. The identified transition structures are geometrically similar to their respective precursors, G-4 and G-2, with the water hydrogen oriented towards the two cerium centers. The $\mathrm{Ce}-\mathrm{H}$ bond distances are 2.34 and $2.80 \AA$ (quartet) and $2.38 \AA$ and $2.79 \AA$ (doublet), respectively. The transition state between structures G-2 and G-4 on one side and H-2 and H-4 on the other side is essentially barrierless, with a calculated activation energy of only $0.6 \mathrm{kcal} / \mathrm{mol}$ (quartet) and $1.3 \mathrm{kcal} / \mathrm{mol}$ (doublet) and relative enthalpies of reaction of $-11.6 \mathrm{kcal} / \mathrm{mol}$ (quartet) and $-21.0 \mathrm{kcal} / \mathrm{mol}$ (doublet).

\section{$\mathrm{H}_{2}$ Production}

The relative positions of the two hydrogen centers is critical for the final $\mathrm{H}_{2}$ formation step. For this reason, we explored a series of possible rearrangement steps. Of the identified structures, I-2 and I-4 feature molecular orientations that act as reasonable precursors to the formation of $\mathrm{H}_{2}$ (Fig. 6). Structures I-2 and I-4 include a new hydroxide bridge between the cerium centers, resulting in the two hydrogens being in close proximity to one another $(\mathrm{H}-\mathrm{H}$ 


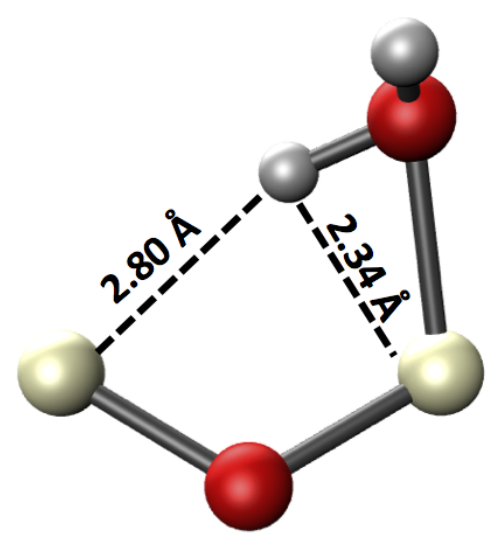

TS1-4

$\Delta H=-11.6$

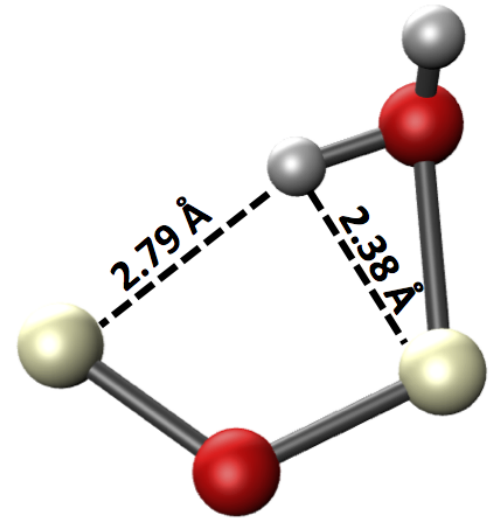

TS1-2

$\Delta H=-21.0$

Figure 5: Structure TS1-4 that connects G-4 and H-4 (left) and TS1-2 that connects G-2 and $\mathrm{H}-2$ (right) with relative energies given in units of $\mathrm{kcal} / \mathrm{mol}$.

distance is $\sim 3 \AA$ ). These structures directly lead to subsequent release of $\mathrm{H}_{2}$ and formation of product clusters $\mathbf{C - 2}$ and $\mathbf{C - 4}$. By comparing the $\mathrm{Ce}-\mathrm{H}$ bond lengths of structures $\mathbf{H}-\mathbf{2}$ and H-4 with I-2 and I-4, we observe a decrease in bond distance as the hydroxide binds to the second cerium atom. Thus the bond formation between the hydroxide and cerium plays a role in decreasing the bond distance between one of the cerium atoms and the other hydrogen center.

Our calculations identified transition structures connecting $\mathbf{H}-\mathbf{2}$ and $\mathbf{H}-\mathbf{4}$ to $\mathbf{I}-\mathbf{2}$ and $\mathbf{I}-\mathbf{4}$, shown in Fig. 7. These transition structures lead to bond formation between the hydroxide and a cerium center. Both doublet and quartet transition structures were confirmed as first-order saddle points by identifying one imaginary frequency. Further confirmation of the nature of the potential energy surface was done using IRC calculations (see supporting information for more details). In both cases, the transition structures present small reaction barriers $(7.6 \mathrm{kcal} / \mathrm{mol}$ for the quartet and $6.5 \mathrm{kcal} / \mathrm{mol}$ for the doublet). In support of experimental interpretations, ${ }^{39,53}$ these transition structures feature an electron rich hydroxide attracted by the electron-poor cerium center resulting in diffuse multi-centered bonds 
Front View
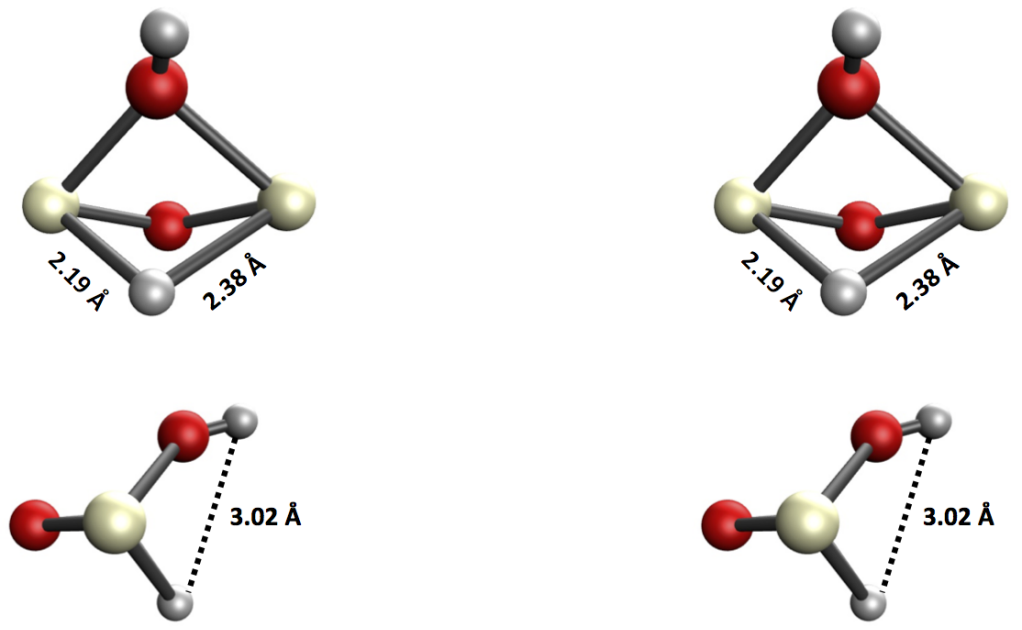

I-4

I-2

$\Delta \mathrm{H}=-\mathbf{6 6 . 6}$

$\Delta \mathrm{H}=\mathbf{- 7 5 . 5}$

Figure 6: Front and side view of the geometry of structures quartet I-4 (left) and doublet I-2 (right) with relative energies given in $\mathrm{kcal} / \mathrm{mol}$.

involving the hydroxide and both cerium atoms.

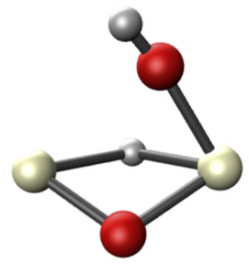

TS2-4

$\Delta \mathrm{H}=-65.4$

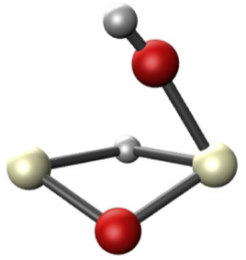

TS2-2

$\Delta \mathrm{H}=\mathbf{- 7 5 . 1}$

Figure 7: Structures of TS2-2 and TS2-4 that connect H-2 and H-4 to I-2 and I-4, respectively and their relative energies (in $\mathrm{kcal} / \mathrm{mol}$ ).

Figure 8 shows structures of the last step of the mechanism, which involves $\mathrm{H}_{2}$ production and formation of $\mathbf{C - 2}$ and $\mathbf{C}-\mathbf{4}$. The relative energies of the separated products (shown in Fig. 8) indicate the exothermic nature of the last step as well as the overall reaction. The enthalpy of reaction for hydrogen gas evolution via a quartet starting material is -91.3 $\mathrm{kcal} / \mathrm{mol}$, while $\Delta \mathrm{H}$ calculated for the doublet is $-100.5 \mathrm{kcal} / \mathrm{mol}$. Moreover, the relative 
energies of the separated products with respect to their precursors, structures I-4 and I-2, are $-24.7 \mathrm{kcal} / \mathrm{mol}$ and $-25.0 \mathrm{kcal} / \mathrm{mol}$, respectively.

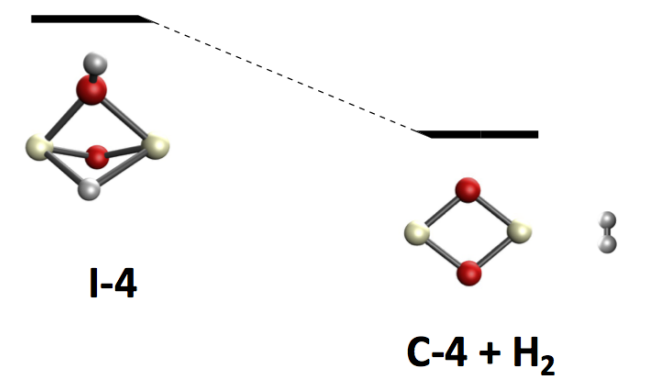

$\Delta \mathrm{H}=-\mathbf{9 1 . 3}$

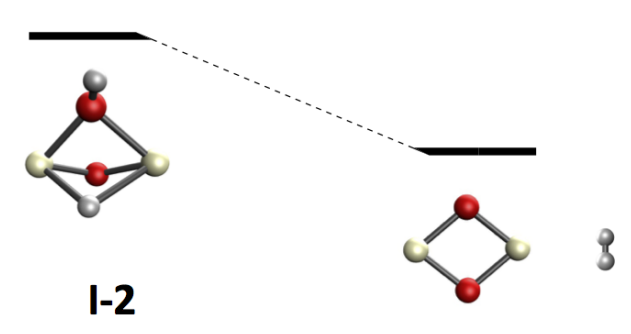

$\mathrm{C}-2+\mathrm{H}_{2}$

$\Delta H=-100.5$

Figure 8: Structures and relative energies (in kcal/mol) of I-4 and C-4 (left) and I-2 and C-2 (right).

\section{Reaction Profiles}

Figure 9 shows the full energy profile of the doublet and quartet mechanistic routes. In both cases the overall reactions are barrierless, in agreement with the experimental data provided by Jarrold and coworkers. ${ }^{39,53}$ Again, the reaction can be summarized by four steps: (1) addition of water onto a cerium center of $\mathrm{Ce}_{2} \mathrm{O}^{-} ;(2)$ hydride transfer from water into a bridging position between the two cerium atoms; (3) bond formation between hydroxide and the far cerium atom; and (4) evolution of $\mathrm{H}_{2}$.

There are features of the $\mathrm{Ce}_{2} \mathrm{O}^{-}$catalyzed reaction that are different from reports published for transition metal oxide cluster analogues. Three such examples include tungsten oxide, molybdenum oxide, and mixed manganese-molybdenum oxides. ${ }^{73-76}$ The overall reaction barriers for those cases is similar to the case reported in this work, but a key difference lies in the mode of addition of water to the clusters. Indeed, previous reports found that the initial steps of water addition occur via a concerted step involving simultaneous addition of hydroxide (from water) to the metal center and $\mathrm{O}-\mathrm{H}$ formation at an oxo site. As discussed 


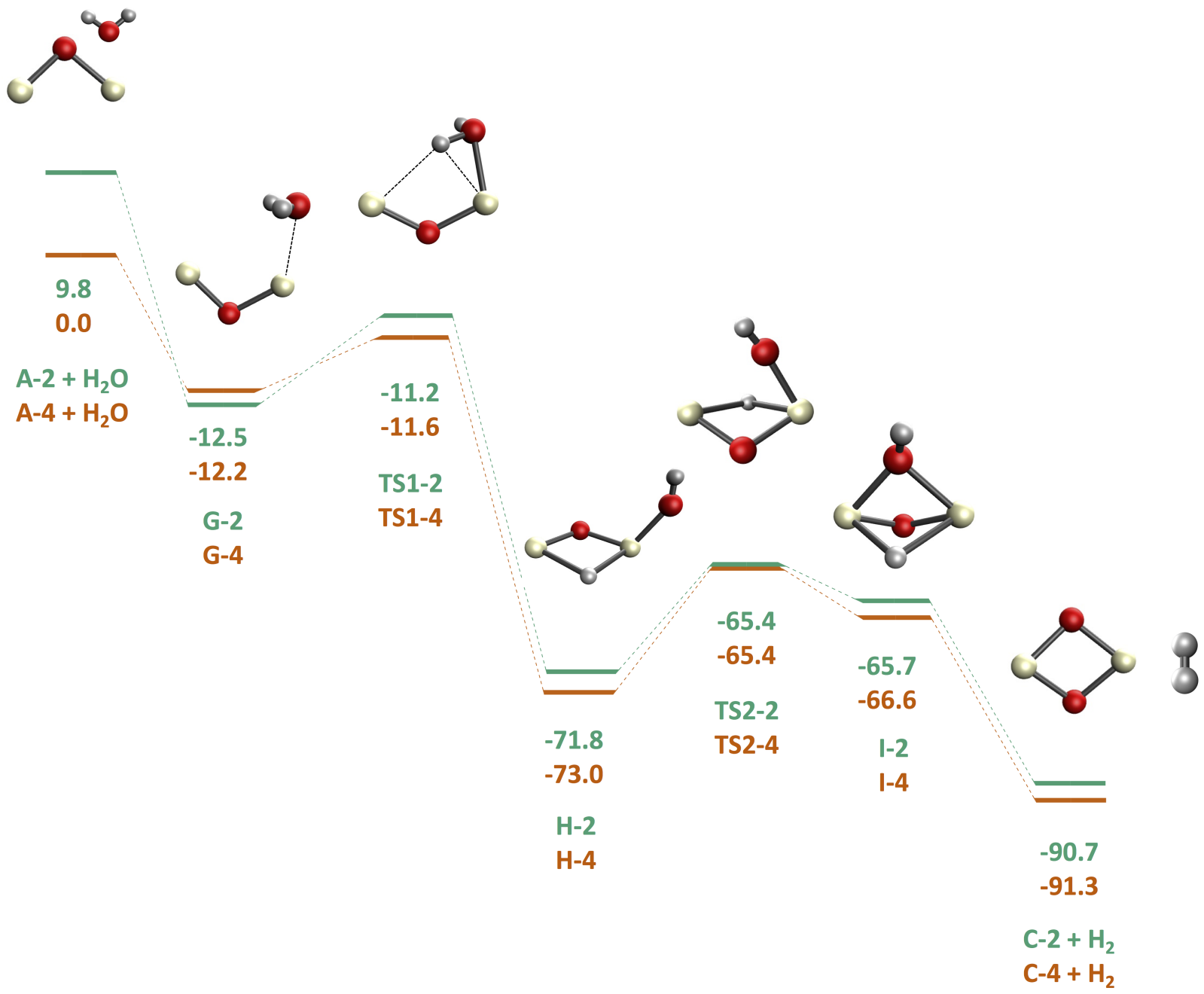

Figure 9: Energy profile for the proposed $\mathrm{Ce}_{2} \mathrm{O}^{-}+\mathrm{H}_{2} \mathrm{O} \longrightarrow \mathrm{Ce}_{2} \mathrm{O}_{2}^{-}+\mathrm{H}_{2}$ quartet (orange) and doublet (green) mechanisms

above, our calculations identified a different pathway for the reaction with cerium oxide that occurs via a two-step process: water adds to the cerium center to form structures G-2 and G-4 (Fig. 3), then the hydrogen transfers to a bridging position between the two cerium centers.

In the reaction of $\mathrm{Mn}_{\mathrm{x}} \mathrm{MoO}_{\mathrm{y}}$ anions with water, both $\mathrm{Mn}$ and $\mathrm{Mo}$ are involved in the initial cluster-water formation. ${ }^{76}$ However, only the Mo center undergoes oxidation. In fact, the reactivity of the $\mathrm{Mn}_{\mathrm{x}} \mathrm{MoO}_{\mathrm{y}}$ anion clusters with water depends on the oxidation state only of the molybdenum center. Once the Mo center reaches its highest oxidation state (VI), 
reaction with additional water molecules ends.

\section{Electronic Structures of Cerium Oxide Clusters}

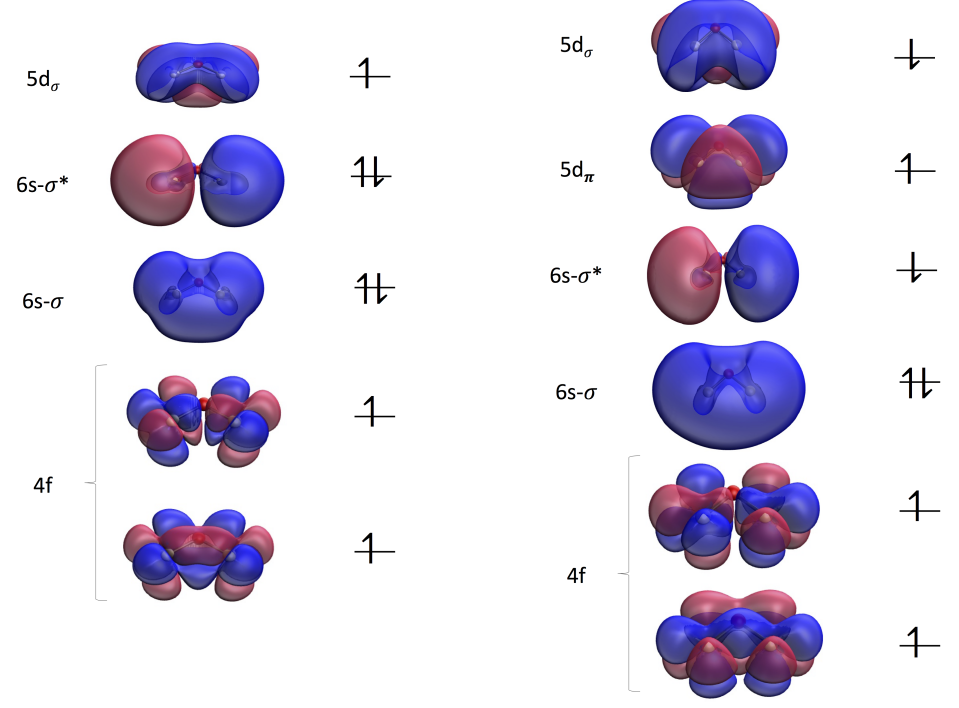

Figure 10: Valence molecular orbitals of quartet (left) and doublet (right) $\mathrm{Ce}_{2} \mathrm{O}^{-}$

Figure 10 shows the frontier molecular orbitals (MOs) of $\mathbf{A - 2}$ and $\mathbf{A - 4}$. The MO diagram of A-4 is comprised of three general manifolds: $4 \mathrm{f}$ orbitals, $\sigma$ and $\sigma^{*}$, and $5 \mathrm{~d}$ orbitals. The first frontier orbital group includes two singly occupied $4 \mathrm{f}$ orbitals localized on the cerium centers. The $\sigma$ and $\sigma^{*}$ orbitals are doubly occupied and are predominantly Ce 6s-based. Finally, the $(\alpha)$ highest occupied $\mathrm{MO}(\mathrm{HOMO})$ of quartet $\mathrm{Ce}_{2} \mathrm{O}^{-}$, is a $5 \mathrm{~d}$-based singly occupied orbital with the electron delocalized over the space spanning the two cerium centers. The shown doublet $\mathrm{Ce}_{2} \mathrm{O}^{-}$MOs include occupied $4 \mathrm{f}$ orbitals localized on the cerium centers and the doubly occupied $\sigma$ orbital. The main difference between A-2 and A-4 MOs lies in the manifold of singly occupied orbitals. Unlike its quartet analogue, the doublet $\mathrm{Ce}_{2} \mathrm{O}^{-}$ exhibits three singly occupied orbitals: one $5 d_{\pi} \alpha$ orbital; one $\sigma^{*} \beta$ orbital; and one $5 d_{\sigma} \beta$ orbital.

MO diagrams for C-2 and C-4 (shown in Fig. 11) exhibit more similarity to each other than A-2 and A-4. Both spin states of structure $\mathbf{C}$ include the two singly occupied $4 \mathrm{f}$ orbitals 
present in their respective starting $\mathbf{A}$ clusters. In addition, both doublet and quartet spin states have a doubly occupied 6 s-based $\sigma$ orbital and a singly occupied $\sigma^{*}$ orbital. The only difference is the spin of the electron occupying the $\sigma^{*}$ orbital. The quartet has an $\alpha$ electron in the $\sigma^{*}$ orbital, while that same orbital is occupied by a $\beta$ electron in the doublet $\mathbf{C - 2}$.

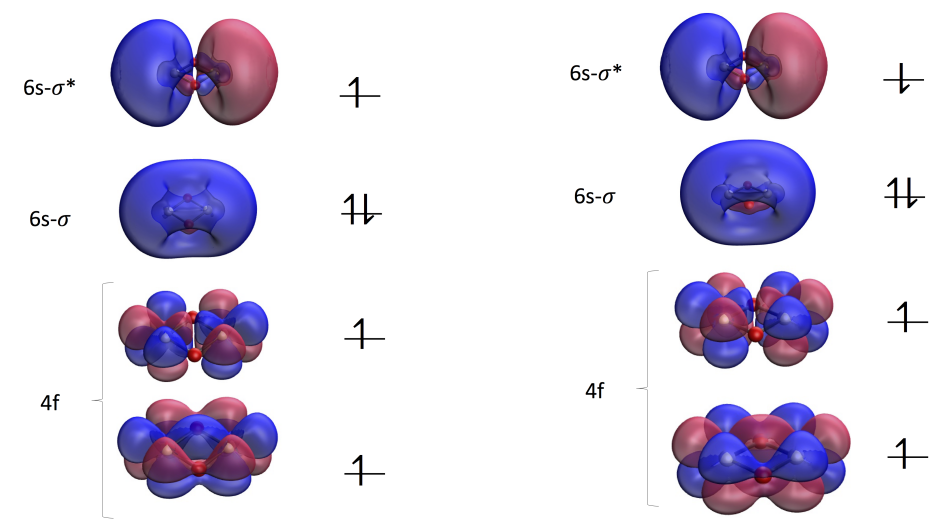

Figure 11: Valence molecular orbitals of quartet (left) and doublet (right) $\mathrm{Ce}_{2} \mathrm{O}_{2}{ }^{-}$

The combined oxidation state of the two cerium centers is $(+\mathrm{I})$ in $\mathrm{Ce}_{2} \mathrm{O}^{-}$and $(+\mathrm{III})$ in $\mathrm{Ce}_{2} \mathrm{O}_{2}{ }^{-}$. Figures 10 and 11 show that the frontier molecular orbitals of both $\mathrm{Ce}_{2} \mathrm{O}^{-}$ and $\mathrm{Ce}_{2} \mathrm{O}_{2}{ }^{-}$exhibit delocalization of electrons over the two cerium metals. In addition, as discussed in the previous sections, all $\mathrm{Ce}-\mathrm{O}$ bonds are equivalent within the same molecule in both the $\mathrm{Ce}_{2} \mathrm{O}^{-}$and $\mathrm{Ce}_{2} \mathrm{O}_{2}^{-}$. For these reasons, the oxidation states of the cerium centers should also be equal. In addition, given the delocalized nature of the frontier orbitals over the two cerium centers, these species can be described by two resonance structures that have cerium centers with unequal oxidation states. For $\mathrm{Ce}_{2} \mathrm{O}^{-}$, the studied structure can be described by two resonance structures of $\mathrm{Ce}_{2} \mathrm{O}^{-}$, with each resonance form featuring one $\mathrm{Ce}(0)$ and one $\mathrm{Ce}(\mathrm{I})$ center. In a similar manner, the final $\mathrm{Ce}_{2} \mathrm{O}_{2}{ }^{-}$structures are described by two $\mathrm{Ce}(\mathrm{I}) / \mathrm{Ce}(\mathrm{II})$ resonance structures.

While the cerium-based 6s orbitals have been previously determined to be the sites of electron detachments in various cerium and cerium suboxide clusters (including $\mathrm{Ce}_{2} \mathrm{O}^{-}$and $\mathrm{Ce}_{2} \mathrm{O}_{2}{ }^{-}$), we notice here that both $\sigma$ and $\sigma^{*}$ orbitals retain all or most of their electron occupations as the reaction proceeds. This shows that $\sigma$ and $\sigma^{*}$ electrons are not the source 
of metal facilitated reduction of water. Instead, the electron source in the studied reaction is the set of singly occupied 5 d orbitals. This observation is consistent with the reported experimental result that reaction of $\mathrm{Ce}_{2} \mathrm{O}_{2}{ }^{-}$with water yields $\mathrm{H}$-radical rather than $\mathrm{H}_{2}$. The reaction of water with $\mathrm{Ce}_{2} \mathrm{O}^{-}$depletes the metal centers of their d electrons and prevents further $\mathrm{H}_{2}$ production. ${ }^{17}$

\section{Conclusions}

This work studied the reaction of water with $\mathrm{Ce}_{2} \mathrm{O}^{-}$clusters to produce $\mathrm{Ce}_{2} \mathrm{O}_{2}{ }^{-}$and $\mathrm{H}_{2}$. Density functional theory calculations have been used to map out the full reaction pathway for hydrogen production. A thorough search for candidate intermediates and transition structures has shown that a key point in the progression of the reaction is the formation of successive bridging bonds that place the two hydrogen atoms in close proximity and eventually facilitates the production of $\mathrm{H}_{2}$. We have also shown that it is energetically possible for both experimentally identified electronic states of $\mathrm{Ce}_{2} \mathrm{O}^{-}$to react with water and eliminate molecular hydrogen with low energy barriers relative to the starting materials. Finally, while the valence molecular orbitals of the studied cerium oxide clusters consist of 4f, 5d, and 6s metal-centered orbitals, an examination of the molecular orbitals of initial and final cerium oxide clusters clearly indicates that the metal $5 \mathrm{~d}$ electrons provide the means for water reduction. This work provides new insight to the reactivity of small lanthanide-based clusters with water.

\section{Acknowledgement}

The authors thank Samantha L. Bidwell (UC Merced) and Professor Caroline Chick Jarrold (Indiana University) for helpful and insightful discussions. The National Science Foundation is gratefully acknowledged for supporting this work (CHE-1848580). Computing time was provided in part by the MERCED cluster at UC Merced, which was also supported by the 
National Science Foundation (ACI-1429783).

\section{References}

(1) Pettersson, L. G. M.; Henchman, R. H.; Nilsson, A. Water - The Most Anomalous Liquid. 2016.

(2) Speedy, R. J. Stability-limit conjecture. An interpretation of the properties of water. J. Phys. Chem. 1982, 86, 982-991.

(3) Poole, P. H.; Sciortino, F.; Essmann, U.; Stanley, H. E. Phase behaviour of metastable water. Nature 1992, 360, 324.

(4) Tanaka, H. Simple physical model of liquid water. J. Chem. Phys. 2000, 112, 799-809.

(5) Holten, V.; Anisimov, M. Entropy-driven liquid-liquid separation in supercooled water. Sci. Rep. 2012, 2, 713.

(6) Smith, J. D.; Cappa, C. D.; Wilson, K. R.; Cohen, R. C.; Geissler, P. L.; Saykally, R. J. Unified description of temperature-dependent hydrogen-bond rearrangements in liquid water. Proc. Natl. Acad. Sci. 2005, 102, 14171-14174.

(7) Liu, J.; Andino, R. S.; Miller, C. M.; Chen, X.; Wilkins, D. M.; Ceriotti, M.; Manolopoulos, D. E. A surface-specific isotope effect in mixtures of light and heavy water. J. Phys. Chem. C 2013, 117, 2944-2951.

(8) Medders, G. R.; Babin, V.; Paesani, F. Development of a "first-principles" water potential with flexible monomers. III. Liquid phase properties. J. Chem. Theory Comput. 2014, 10, 2906-2910.

(9) Bartók, A. P.; Payne, M. C.; Kondor, R.; Csányi, G. Gaussian approximation potentials: The accuracy of quantum mechanics, without the electrons. Phys. Rev. Lett. 2010, 104, 136403. 
(10) Gillan, M. J.; Alfè, D.; Michaelides, A. Perspective: How good is DFT for water? J. Chem. Phys. 2016, 144, 130901.

(11) Gallo, P.; Amann-Winkel, K.; Angell, C. A.; Anisimov, M. A.; Caupin, F.; Chakravarty, C.; Lascaris, E.; Loerting, T.; Panagiotopoulos, A. Z.; Russo, J., et al. Water: A tale of two liquids. Chem. Rev. 2016, 116, 7463-7500.

(12) Hunter, B. M.; Gray, H. B.; Muller, A. M. Earth-abundant heterogeneous water oxidation catalysts. Chem. Rev. 2016, 116, 14120-14136.

(13) McEvoy, J. P.; Brudvig, G. W. Water-splitting chemistry of photosystem II. Chem. Rev. 2006, 106, 4455-4483.

(14) Walter, M. G.; Warren, E. L.; McKone, J. R.; Boettcher, S. W.; Mi, Q.; Santori, E. A.; Lewis, N. S. Solar water splitting cells. Chem. Rev. 2010, 110, 6446-6473.

(15) Tachibana, Y.; Vayssieres, L.; Durrant, J. R. Artificial photosynthesis for solar watersplitting. Nat. Photonics 2012, 6, 511.

(16) Kang, D.; Kim, T. W.; Kubota, S. R.; Cardiel, A. C.; Cha, H. G.; Choi, K.-S. Electrochemical synthesis of photoelectrodes and catalysts for use in solar water splitting. Chem. Rev. 2015, 115, 12839-12887.

(17) Felton, J. A.; Ray, M.; Waller, S. E.; Kafader, J. O.; Jarrold, C. C. $\mathrm{Ce}_{\mathrm{x}} \mathrm{O}_{\mathrm{y}}{ }^{-}$(x= 2-3) $+\mathrm{D}_{2} \mathrm{O}$ Reactions: Stoichiometric Cluster Formation from Deuteroxide Decomposition and Anti-Arrhenius Behavior. J. Phys. Chem. A 2014, 118, 9960-9969.

(18) Graciani, J.; Márquez, A. M.; Plata, J. J.; Ortega, Y.; Hernández, N. C.; Meyer, A.; Zicovich-Wilson, C. M.; Sanz, J. F. Comparative study on the performance of hybrid DFT functionals in highly correlated oxides: The case of $\mathrm{CeO}_{2}$ and $\mathrm{Ce}_{2} \mathrm{O}_{3}$. J. Chem. Theory Comput. 2010, 7, 56-65. 
(19) Wu, X.-N.; Ding, X.-L.; Bai, S.-M.; Xu, B.; He, S.-G.; Shi, Q. Experimental and Theoretical Study of the Reactions between Cerium Oxide Cluster Anions and Carbon Monoxide: Size-Dependent Reactivity of $\mathrm{Ce}_{\mathrm{n}} \mathrm{O}_{2 \mathrm{n}+1}{ }^{-}(\mathrm{n}=1-21)$. J. Phys. Chem. C 2011, 115, 13329-13337.

(20) Nagata, T.; Miyajima, K.; Mafuné, F. Gold Atoms Supported on Gas-Phase Cerium Oxide Cluster Ions: Stable Stoichiometry and Reactivity with CO. J. Phys. Chem. A 2016, 120, 7624-7633.

(21) Nagata, T.; Miyajima, K.; Mafuné, F. Oxidation of nitric oxide on gas-phase cerium oxide clusters via reactant adsorption and product desorption processes. J. Phys. Chem. A 2015, 119, 10255-10263.

(22) Zhao, Y.-X.; Liu, Q.-Y.; Zhang, M.-Q.; He, S.-G. Reactions of metal cluster anions with inorganic and organic molecules in the gas phase. Dalton Trans. 2016, 45, 11471-11495.

(23) Idakiev, V.; Tabakova, T.; Tenchev, K.; Yuan, Z.-Y.; Ren, T.-Z.; Su, B.-L. Gold nanoparticles supported on ceria-modified mesoporous titania as highly active catalysts for low-temperature water-gas shift reaction. Catal. Today 2007, 128, 223-229.

(24) Fu, Q.; Saltsburg, H.; Flytzani-Stephanopoulos, M. Active nonmetallic Au and Pt species on ceria-based water-gas shift catalysts. Science 2003, 301, 935-938.

(25) Martınez-Arias, A.; Fernández-Garcia, M.; Soria, J.; Conesa, J. Spectroscopic study of a $\mathrm{Cu} / \mathrm{CeO}_{2}$ catalyst subjected to redox treatments in carbon monoxide and oxygen. $J$. Catal. 1999, 182, 367-377.

(26) Takamura, H.; Kobayashi, T.; Kasahara, T.; Kamegawa, A.; Okada, M. Oxygen permeation and methane reforming properties of ceria-based composite membranes. Journal of alloys and compounds 2006, 408, 1084-1089. 
(27) Fernández-Garcia, M.; Martınez-Arias, A.; Salamanca, L.; Coronado, J.; Anderson, J.; Conesa, J.; Soria, J. Influence of ceria on $\mathrm{Pd}$ activity for the $\mathrm{CO}+\mathrm{O}_{2}$ reaction. J. Catal. $1999,187,474-485$.

(28) Esposito, V.; Traversa, E. Design of electroceramics for solid oxides fuel cell applications: playing with ceria. J. Am. Ceram. Soc. 2008, 91, 1037-1051.

(29) Aneggi, E.; Boaro, M.; de Leitenburg, C.; Dolcetti, G.; Trovarelli, A. Insights into the redox properties of ceria-based oxides and their implications in catalysis. J. Alloys Compd. 2006, 408, 1096-1102.

(30) Gorte, R. J. Ceria in catalysis: From automotive applications to the water-gas shift reaction. AIChE J. 2010, 56, 1126-1135.

(31) Saraf, L.; Wang, C. M.; Shutthanandan, V.; Zhang, Y.; Marina, O.; Baer, D. R.; Thevuthasan, S.; Nachimuthu, P.; Lindle, D. W. Oxygen transport studies in nanocrystalline ceria films. J. Mater. Res. 2005, 20, 1295-1299.

(32) Montini, T.; Melchionna, M.; Monai, M.; Fornasiero, P. Fundamentals and catalytic applications of $\mathrm{CeO}_{2}$-based materials. Chem. Rev. 2016, 116, 5987-6041.

(33) Li, Y.; Fu, Q.; Flytzani-Stephanopoulos, M. Low-temperature water-gas shift reaction over $\mathrm{Cu}$-and Ni-loaded cerium oxide catalysts. Appl. Catal., B 2000, 27, 179-191.

(34) Bunluesin, T.; Gorte, R.; Graham, G. Studies of the water-gas-shift reaction on ceriasupported Pt, Pd, and Rh: implications for oxygen-storage properties. Appl. Catal., B $1998,15,107-114$.

(35) Luengnaruemitchai, A.; Osuwan, S.; Gulari, E. Comparative studies of low-temperature water-gas shift reaction over $\mathrm{Pt} / \mathrm{CeO}_{2}, \mathrm{Au} / \mathrm{CeO}_{2}$, and $\mathrm{Au} / \mathrm{Fe}_{2} \mathrm{O}_{3}$ catalysts. Catal. Commun. 2003, 4, 215-221. 
(36) Biswas, S.; Husek, J.; Londo, S.; Baker, L. R. Highly localized charge transfer excitons in metal oxide semiconductors. Nano Lett. 2018, 18, 1228-1233.

(37) Harb, H.; Thompson, L. M.; Hratchian, H. P. On the linear geometry of lanthanide hydroxide (Ln-OH, Ln= La-Lu). Phys. Chem. Chem. Phys. 2019, 21, 21890-21897.

(38) Mason, J. L.; Harb, H.; Topolski, J. E.; Hratchian, H. P.; Jarrold, C. C. Exceptionally Complex Electronic Structures of Lanthanide Oxides and Small Molecules. Acc. Chem. Res. 2019, 52, 3265-3273.

(39) Kafader, J. O.; Topolski, J. E.; Jarrold, C. C. Molecular and electronic structures of cerium and cerium suboxide clusters. J. Chem. Phys. 2016, 145, 154306.

(40) Maron, L.; Eisenstein, O. Do f Electrons Play a Role in the Lanthanide- Ligand Bonds? A DFT Study of $\operatorname{Ln}\left(\mathrm{NR}_{2}\right)_{3} ; \mathrm{R}=\mathrm{H}, \mathrm{SiH}_{3}$. J. Phys. Chem. A 2000, 104, 7140-7143.

(41) Eisenstein, O.; Maron, L. DFT studies of some structures and reactions of lanthanides complexes. J. Organomet. Chem. 2002, 647, 190-197.

(42) Kafader, J. O.; Ray, M.; Jarrold, C. C. Photoelectron spectrum of $\mathrm{PrO}^{-}$. J. Chem. Phys. 2015, 143, 064305.

(43) Roos, B. O.; Pyykkö, P. Bonding Trends in Molecular Compounds of Lanthanides: The Double-Bonded Carbene Cations $\mathrm{LnCH}_{2}{ }^{+}(\mathrm{Ln}=\mathrm{Sc}, \mathrm{Y}, \mathrm{La}-\mathrm{Lu})$. Chem. - Eur. J. 2010, 16, 270-275.

(44) Zhou, R.; Yang, Y.; Pande, S.; Qu, B.; Li, D.; Zeng, X. C. Reaction mechanism between small-sized Ce clusters and water molecules: an ab initio investigation on $\mathrm{Ce}_{\mathrm{n}}+\mathrm{H}_{2} \mathrm{O}$. Phys. Chem. Chem. Phys. 2019, 21, 4006-4014.

(45) Zhou, R.; Ma, S.; Yang, Y.; Li, D.; Qu, B.; Zeng, X. C. Reaction mechanism between small-sized Ce clusters and water molecules II: an ab initio investigation on $\mathrm{Ce}_{\mathrm{n}}(\mathrm{n}=$ 1-3) $+\mathrm{m} \mathrm{H}_{2} \mathrm{O}(\mathrm{m}=2-6)$. Phys. Chem. Chem. Phys. 2019, 21, 8945-8955. 
(46) Li, Y.; Gong, Y.; Zhou, X.; Su, J.; Li, J.; Zhou, M. Infrared spectroscopic and theoretical study of the reactions of cerium atoms with methanol in solid argon. J. Mol. Spectrosc. 2015, 310, 50-56.

(47) Xu, B.; Shi, P.; Huang, T.; Wang, X. Hydrogen-bridge $\mathrm{Si}(\mu-\mathrm{H})_{3} \mathrm{CeH}$ and inserted $\mathrm{H}_{3} \mathrm{SiCeH}$ molecules: Matrix infrared spectra and DFT calculations for reaction products of silane with Ce atoms. J. Mol. Struct. 2017, 1146, 692-702.

(48) Wang, X.; Andrews, L.; Fang, Z.; Thanthiriwatte, K. S.; Chen, M.; Dixon, D. A. Properties of Lanthanide Hydroxide Molecules Produced in Reactions of Lanthanide Atoms with $\mathrm{H}_{2} \mathrm{O}_{2}$ and $\mathrm{H}_{2}+\mathrm{O}_{2}$ Mixtures: Roles of the $+\mathrm{I},+\mathrm{II},+\mathrm{III}$, and $+\mathrm{IV}$ Oxidation States. J. Phys. Chem. A 2017, 121, 1779-1796.

(49) Fang, Z.; Thanthiriwatte, K. S.; Dixon, D. A.; Andrews, L.; Wang, X. Properties of cerium hydroxides from matrix infrared spectra and electronic structure calculations. Inorg. Chem. 2016, 55, 1702-1714.

(50) Pu, Z.; Yu, W.; Roy, S. K.; Li, C.; Ao, B.; Liu, T.; Shuai, M.; Wang, X. Insights into the enhanced CeN triple bond in the HCeN molecule. Phys. Chem. Chem. Phys. 2017, $19,8216-8222$.

(51) Mikulas, T. C.; Chen, M.; Fang, Z.; Peterson, K. A.; Andrews, L.; Dixon, D. A. Structures and Properties of the Products of the Reaction of Lanthanide Atoms with $\mathrm{H}_{2} \mathrm{O}$ : Dominance of the +II Oxidation State. J. Phys. Chem. A 2016, 120, 793-804.

(52) Kafader, J. O.; Ray, M.; Jarrold, C. C. Low-lying electronic structure of EuH, EuOH, and $\mathrm{EuO}$ neutrals and anions determined by anion photoelectron spectroscopy and DFT calculations. J. Chem. Phys. 2015, 143, 034305.

(53) Topolski, J.; Kafader, J.; Ray, M.; Jarrold, C. Elucidating cerium $+\mathrm{H}_{2} \mathrm{O}$ reactivity through electronic structure: A combined PES and DFT study. J. Mol. Spectrosc. 2017, 336, 1-11. 
(54) Ray, M.; Kafader, J. O.; Topolski, J. E.; Jarrold, C. C. Mixed cerium-platinum oxides: Electronic structure of $[\mathrm{CeO}] \mathrm{Pt}_{\mathrm{n}}(\mathrm{n}=1,2)$ and $\left[\mathrm{CeO}_{2}\right] \mathrm{Pt}$ complex anions and neutrals. J. Chem. Phys. 2016, 145, 044317.

(55) Topolski, J. E.; Kafader, J. O.; Jarrold, C. C. Ce in the +4 oxidation state: Anion photoelectron spectroscopy and photodissociation of small $\mathrm{Ce}_{\mathrm{x}} \mathrm{O}_{\mathrm{y}} \mathrm{H}_{\mathrm{z}}{ }^{-}$molecules. J. Chem. Phys. 2017, 147, 104303.

(56) Topolski, J. E.; Kafader, J. O.; Marrero-Colon, V.; Iyengar, S. S.; Hratchian, H. P.; Jarrold, C. C. Exotic electronic structures of $\mathrm{Sm}_{\mathrm{x}} \mathrm{Ce}_{3-\mathrm{x}} \mathrm{O}_{\mathrm{y}}(\mathrm{x}=0-3 ; \mathrm{y}=2-4)$ clusters and the effect of high neutral density of low-lying states on photodetachment transition intensities. J. Chem. Phys. 2018, 149, 054305.

(57) Frisch, M. J.; Trucks, G. W.; Schlegel, H. B.; Scuseria, G. E.; Robb, M. A.; Cheeseman, J. R.; Scalmani, G.; Barone, V.; Petersson, G. A.; Nakatsuji, H.; Li, X.; Caricato, M.; Marenich, A. V.; Bloino, J.; Janesko, B. G.; Gomperts, R.; Mennucci, B.; Hratchian, H. P.; Ortiz, J. V.; Izmaylov, A. F.; Sonnenberg, J. L.; WilliamsYoung, D.; Ding, F.; Lipparini, F.; Egidi, F.; Goings, J.; Peng, B.; Petrone, A.; Henderson, T.; Ranasinghe, D.; Zakrzewski, V. G.; Gao, J.; Rega, N.; Zheng, G.; Liang, W.; Hada, M.; Ehara, M.; Toyota, K.; Fukuda, R.; Hasegawa, J.; Ishida, M.; Nakajima, T.; Honda, Y.; Kitao, O.; Nakai, H.; Vreven, T.; Throssell, K.; Montgomery, J. A., Jr.; Peralta, J. E.; Ogliaro, F.; Bearpark, M. J.; Heyd, J. J.; Brothers, E. N.; Kudin, K. N.; Staroverov, V. N.; Keith, T. A.; Kobayashi, R.; Normand, J.; Raghavachari, K.; Rendell, A. P.; Burant, J. C.; Iyengar, S. S.; Tomasi, J.; Cossi, M.; Millam, J. M.; Klene, M.; Adamo, C.; Cammi, R.; Ochterski, J. W.; Martin, R. L.; Morokuma, K.; Farkas, O.; Foresman, J. B.; Fox, D. J. Gaussian Development Version Revision J.04+. 2019; Gaussian Inc. Wallingford CT.

(58) Perdew, J. P.; Chevary, J. A.; Vosko, S. H.; Jackson, K. A.; Pederson, M. R.; Singh, D. J.; Fiolhais, C. Atoms, molecules, solids, and surfaces: Applications of the 
generalized gradient approximation for exchange and correlation. Phys. Rev. B 1992, 46,6671 .

(59) Perdew, J. P.; Wang, Y. Accurate and simple analytic representation of the electron-gas correlation energy. Phys. Rev. B 1992, 45, 13244.

(60) Becke, A. D. Density-functional thermochemistry. IV. A new dynamical correlation functional and implications for exact-exchange mixing. J. Chem. Phys. 1996, 104, $1040-1046$.

(61) Becke, A. D. Density-functional thermochemistry. III. The role of exact exchange. $J$. Chem. Phys. 1993, 98, 5648-5652.

(62) Becke, A. D. Density-functional thermochemistry. II. The effect of the Perdew-Wang generalized-gradient correlation correction. J. Chem. Phys. 1992, 97, 9173-9177.

(63) Pople, J.; Nesbet, R. Self-consistent orbitals for radicals. J. Chem. Phys. 1954, 22, $571-572$.

(64) Cao, X.; Dolg, M. Valence basis sets for relativistic energy-consistent small-core lanthanide pseudopotentials. J. Chem. Phys. 2001, 115, 7348-7355.

(65) Kendall, R. A.; Dunning Jr, T. H.; Harrison, R. J. Electron affinities of the first-row atoms revisited. Systematic basis sets and wave functions. J. Chem. Phys. 1992, 96, 6796-6806.

(66) Papajak, E.; Zheng, J.; Xu, X.; Leverentz, H. R.; Truhlar, D. G. Perspectives on basis sets beautiful: seasonal plantings of diffuse basis functions. J. Chem. Theory Comput. 2011, 7, 3027-3034.

(67) Hratchian, H. P.; Schlegel, H. B. Theory and Applications of Computational Chemistry; Elsevier, 2005; pp 195-249. 
(68) Hratchian, H. P.; Schlegel, H. B. Accurate reaction paths using a Hessian based predictor-corrector integrator. J. Chem. Phys. 2004, 120, 9918-9924.

(69) Hratchian, H.; Schlegel, H. Using Hessian updating to increase the efficiency of a Hessian based predictor-corrector reaction path following method. J. Chem. Theory Comput. 2005, 1, 61-69.

(70) Bauernschmitt, R.; Ahlrichs, R. Stability analysis for solutions of the closed shell KohnSham equation. J. Chem. Phys. 1996, 104, 9047-9052.

(71) Seeger, R.; Pople, J. A. Self-consistent molecular orbital methods. XVIII. Constraints and stability in Hartree-Fock theory. J. Chem. Phys. 1977, 66, 3045-3050.

(72) Sonnenberg, J. L.; Schlegel, H. B.; Hratchian, H. P. Spin contamination in inorganic chemistry calculations. Encyclopedia of Inorganic and Bioinorganic Chemistry 2011,

(73) Mayhall, N. J.; Rothgeb, D. W.; Hossain, E.; Jarrold, C. C.; Raghavachari, K. Water reactivity with tungsten oxides: $\mathrm{H}_{2}$ production and kinetic traps. J. Chem. Phys. 2009, 131, 144302.

(74) Mayhall, N. J.; Raghavachari, K. Two Methanes are Better than One: A Density Functional Theory Study of the Reactions of $\mathrm{Mo}_{2} \mathrm{O}_{\mathrm{y}}{ }^{-}(\mathrm{y}=2-5)$ with Methane. J. Phys. Chem. A 2007, 111, 8211-8217.

(75) Yoder, B. L.; Maze, J. T.; Raghavachari, K.; Jarrold, C. C. Structures of $\mathrm{Mo}_{2} \mathrm{O}_{\mathrm{y}}{ }^{-}$ and $\mathrm{Mo}_{2} \mathrm{O}_{\mathrm{y}}(\mathrm{y}=2,3$, and 4$)$ studied by anion photoelectron spectroscopy and density functional theory calculations. J. Chem. Phys. 2005, 122, 094313.

(76) Mason, J. L.; Gupta, A. K.; McMahon, A. J.; Folluo, C. N.; Raghavachari, K.; Jarrold, C. C. The striking influence of oxophilicity differences in heterometallic Mo-Mn oxide cluster reactions with water. J. Chem. Phys. 2020, 152, 054301. 


\section{Graphical TOC Entry}

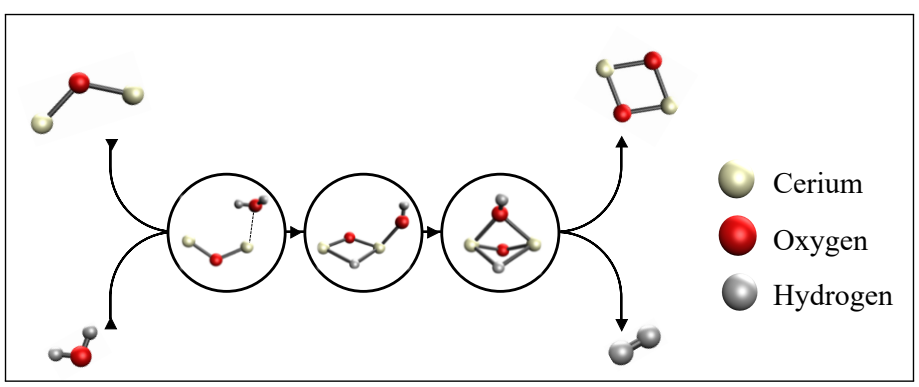

